\title{
Federation of Gynecology and Obstetrics
}

National Cancer Institute

\section{Source}

National Cancer Institute. Federation of Gynecology and Obstetrics. NCI Thesaurus.

Code C89808.

An international organization with a mission to promote the wellbeing of women and to raise the standards of practice in obstetrics and gynecology. They are the creator of staging criteria to describe the extent and spread of gynecologic malignancies. 